\title{
Transforming the food system to fight non-communicable diseases
}

\author{
Malnutrition and unhealthy diets are important risk factors for non-communicable diseases. \\ Francesco Branca and colleagues call for changes in both what and how food is produced,
} marketed, and consumed

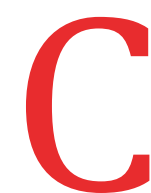
ardiovascular and respiratory diseases, cancers, and diabetes are responsible for $71 \%$ of global deaths (41 million) each year. ${ }^{1}$ Around $85 \%$ of premature deaths from non-communicable diseases (NCDs) now occur in low and middle income countries, ${ }^{2}$ where people also bear the greater burden of undernutrition and infectious disease. ${ }^{1}$ In wealthier countries, NCDs disproportionately affect vulnerable and disadvantaged groups. ${ }^{2}$

Malnutrition is a key risk factor for NCDs. ${ }^{3}$ Globally, nearly one in three people has at least one form of malnutrition, ${ }^{4}$ and this will reach one in two by 2025, based

\section{KEY MESSAGES}

- Poor quality diets, malnutrition in all its forms, and NCDs are closely linked. Unhealthy diets are now the biggest risk factor for NCDs

- Poor quality diets, malnutrition, and NCDs are the logical consequences of, among other factors, major changes to how food is produced, sold, marketed, and consumed around the world in the past half century

- Transformation of current food systems to improve availability, affordability, and uptake of nutritious, safe, affordable, and sustainable diets is key to tackling malnutrition in all its forms and diet related NCDs

- Policy options to tackle the different forms of malnutrition and diet related NCDs can also help create food systems that are sustainable, benefitting planetary health

- The United Nations Decade of Action on Nutrition, along with the 2030 Sustainable Development Agenda and Goals, are a once-in-a-lifetime opportunity to simultaneously and cost effectively improve diets, eliminate malnutrition, reduce death and disability from NCDs, and promote sustainable development on current trends. ${ }^{5}$ Malnutrition includes nutritional disorders caused by deficient intake of energy or nutrients, such as stunting, wasting, and micronutrient deficiencies. It also includes excessive and imbalanced intake, leading to overweight, obesity, and diet related NCDs. Both categories of malnutrition are caused by unhealthy, poor quality diets, and they can be linked. Undernutrition in childhood, in addition to affecting survival, growth, development, health, and educational or economic outcomes, is a risk factor for overweight and NCDs in later life. ${ }^{6}$ Around 151 million children whose stunted growth is caused by undernutrition and 38 million children under five who are currently overweight are at increased risk of NCDs in adulthood. ${ }^{4}$

\section{How unhealthy diets and food systems relate to NCDs}

Unhealthy diets, malnutrition, and NCDs are closely linked. They are the logical consequences of, among other factors, today's food systems, which have changed dramatically in the past 50 years. A focus on efficiency has seen an increase in the availability of inexpensive, high calorie foods, often from staple cereal crops, which has reduced hunger for many. This has, however, often been at the expense of diversity and has displaced local, often healthier, diets. Access to diverse, micronutrient rich foods-such as fresh fruits, vegetables, legumes, pulses, and nuts-has not improved equally for everyone, and unhealthy foods with salt, sugars, saturated fats, and trans fats have become cheaper and more widely available. ${ }^{3}$ Furthermore, global demand for and supply of meat, dairy products, sugar sweetened drinks, and processed and ultra-processed foods has increased dramatically. $^{3}$

A variety of drivers and policies (or the lack thereof) shape food systems (fig 1). Food systems worldwide face major challenges, such as population growth, globalisation, urbanisation, and climate change. Agricultural, economic, trade, environmental, and international development policies create incentives, and disincentives, for the production of particular types of food. Rural development, urban planning, and transport policies affect what food reaches which consumers and at what price. Many factors influence consumers' dietary behaviours, from personalsuch as culture, knowledge, skills, dietary preferences, and time for food preparation-to economic and politicalsuch as the cost or availability of food. Information about food, whether through education or marketing, also influences choices. Marketing, labelling, and policies that impact on price all affect consumer demand. Economic and social protection policies determine whether vulnerable populations can access healthy and sustainable diets. The nutritional quality of the foods available in the places we live affects the health of people and the planet.

Today's food systems are broken and do not deliver nutritious, safe, affordable, and sustainable diets; worse, they undermine nutrition in several ways, particularly for vulnerable and marginalised populations. Good nutrition-particularly in the 1000 days from conception to a child's second birthday-is critical, but aggressive marketing of formula and baby foods compromise breastfeeding and feeding practices in early childhood. Diets lacking a range of nutrient rich foods are a major cause of stunting: two thirds of the world's children are not eating the recommended minimum number of food groups and only one in six children is receiving a minimum acceptable diet. ${ }^{8}$ Billions of dollars are spent annually marketing foods high in calories, fats, sugars, and salt, and intake has increased globally, including in low income countries. Meanwhile, more than a quarter $(27.5 \%)$ of the world's population are now insufficiently physically active. ${ }^{9}$ The prevalence of adult obesity has nearly 


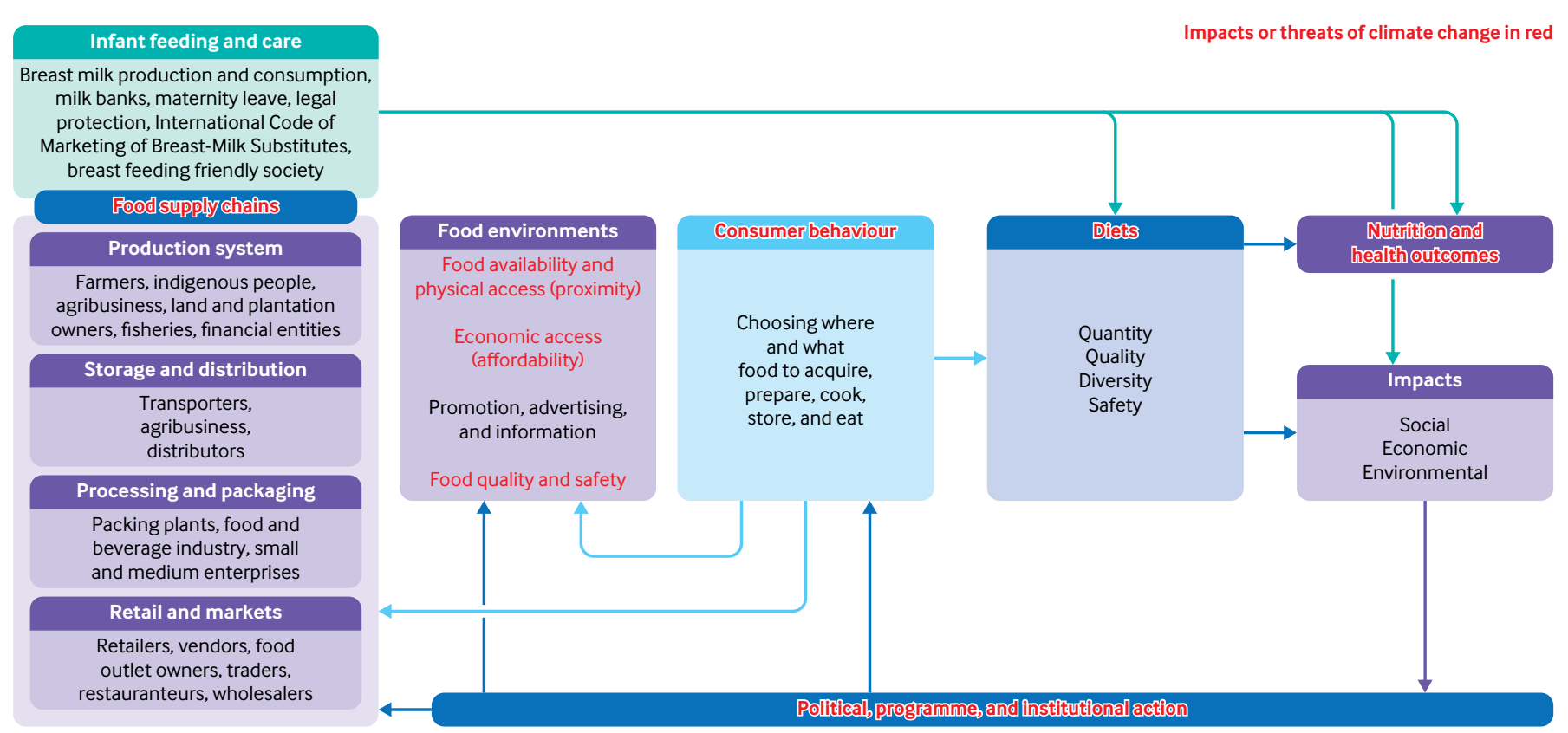

Fig 1 | Food systems and how they affect diet and nutrition. A food system is defined by the High Level Panel of Experts on Food Security and Nutrition of the Committee on World Food Security as including "all the elements (environment, people, inputs, processes, infrastructure, institutions) and activities that relate to the pre-production, production, processing, distribution, preparation, and consumption of food and the outputs of these activities, including socioeconomic and environmental outcomes." Food systems are influenced by sociocultural, economic, political, and environmental contexts. There are many different types of food systems-from long chain, high value, and industrial to short chain, low value, traditional, and rural-and different systems may exist within a country at the same time. The food environment can be defined as "the interface that mediates people's food acquisition and consumption within the wider food system. It encompasses external dimensions such as the availability, prices, vendor and product properties, and promotional information and personal dimensions such as the accessibility, affordability, convenience, and desirability of food sources and products."7

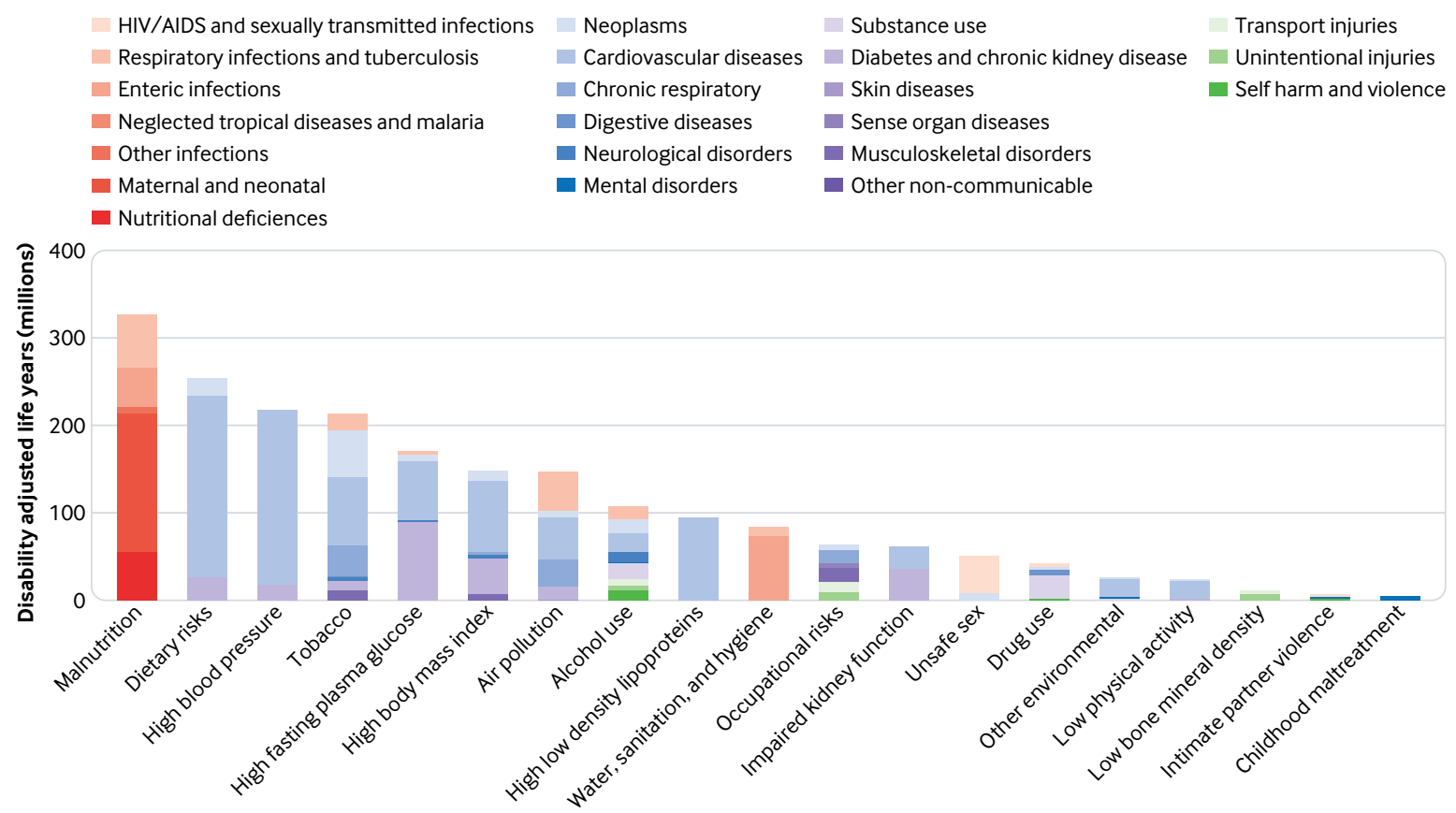

Fig 2 | Contribution of behavioural, metabolic, and environmental risk factors to death and disability (Global total disability adjusted life years, both sexes, all ages, 2017).$^{13}$ Maternal and child malnutrition comprises (in descending order of DALYs lost) low birth weight and short gestation, child growth failure (stunting, wasting, and underweight), iron deficiency, suboptimal breastfeeding, vitamin A deficiency, and zinc deficiency. Dietary risks include low whole grains; low fruit; low nuts and seeds; high sodium; low vegetables; low omega-3; low fibre; low legumes; low polyunsaturated fatty acids; high trans fat; low calcium; high processed meat; low milk; high red meat; high sweetened beverages 


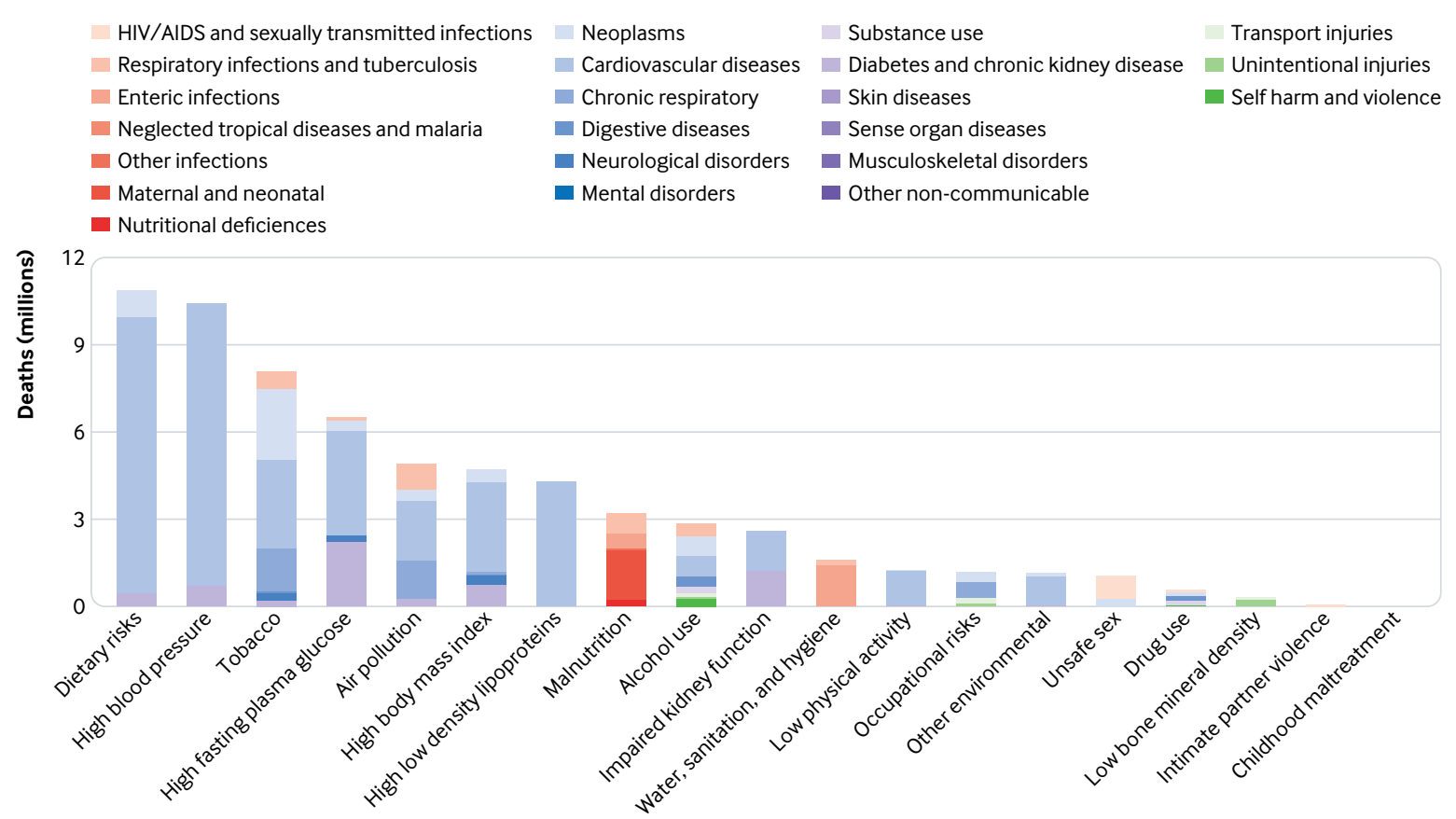

Fig 3 | Risk factor contribution to deaths. Global deaths by risk factor for all ages, both sexes, 2017. Dietary risks include low whole grains; low fruit; low nuts and seeds; high sodium; low vegetables; low omega-3; low fibre; low legumes; low polyunsaturated fatty acids; high trans fat; low calcium; high processed meat; low milk; high red meat; high sweetened beverages ${ }^{13}$

tripled since 1975 and, by 2016, more than 1.9 billion adults were overweight or obese, ${ }^{10}$ while there has been a ten fold increase in overweight and obesity among children and adolescents over the same period. ${ }^{11}$ In 2014, 422 million people were affected by diabetes, up from 108 million in $1980 .^{12}$

\section{The burden and true costs of malnutrition and diet related NCDs}

Maternal and child malnutrition and poor diets are the two major risk factors for disease burden-as measured by disability adjusted life years (DALYs)-worldwide, according to the 2017 Global Burden of Disease data (fig 2). ${ }^{13}$ Poor diet, as defined by a cluster of dietary risks, is the leading cause of death (fig 3) and is the first or second biggest contributor to NCD disease burden in all six World Health Organization regions. ${ }^{13}$

Of these dietary risks, the biggest contributors to the global burden of disease in 2017 were diets that are low in whole grains, high in sodium, or low in

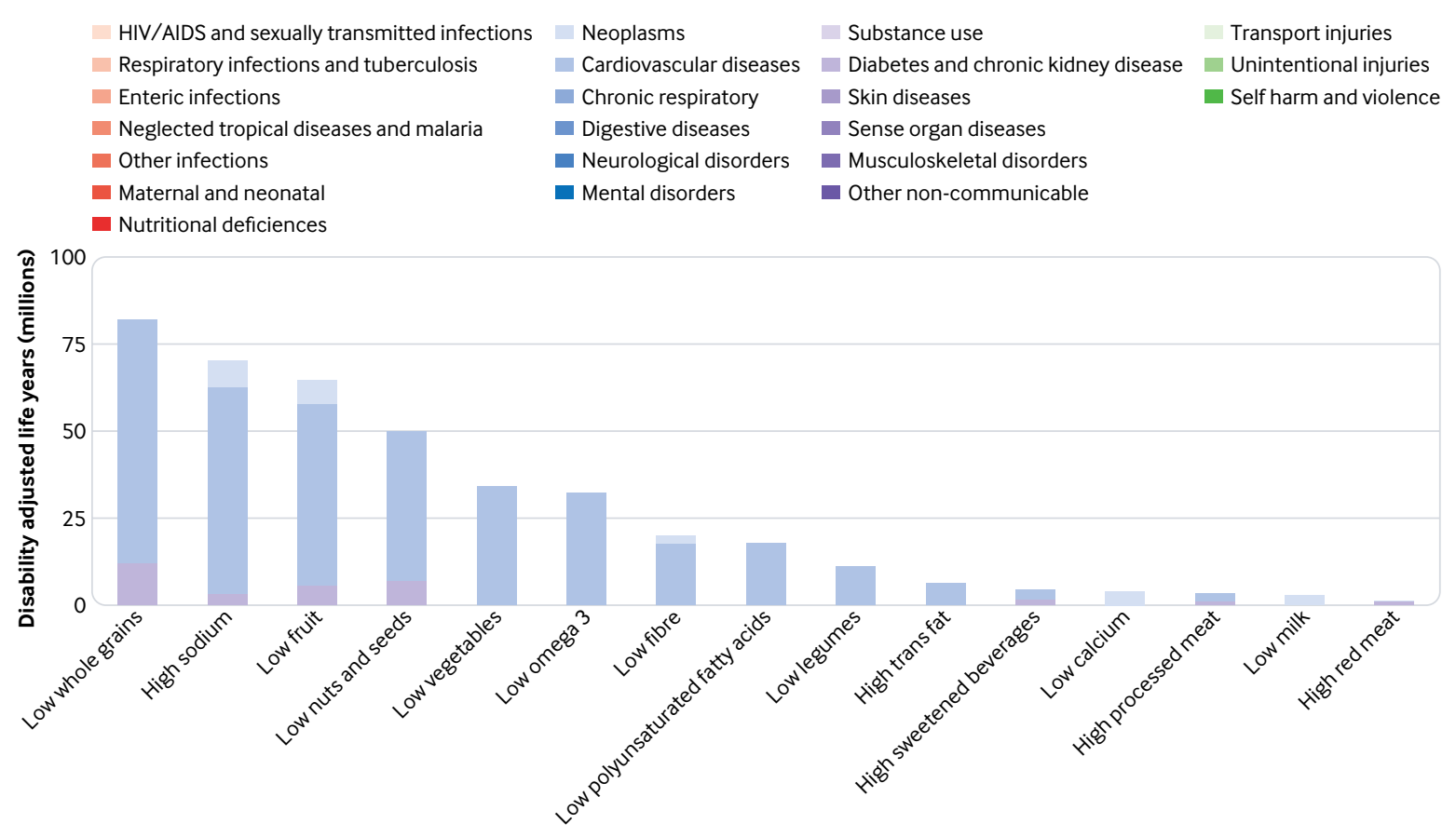

Fig 4 | Specific dietary risk factor contribution to disease burden. Total DALYs lost by dietary risk factor, global, all ages, both sexes, $2017^{13}$ 
fruits, nuts and seeds, or vegetables (fig 4). Additionally, there is an effect of higher body mass index on disease outcomes. ${ }^{13}$

As well as human loss and suffering, malnutrition and diet related NCDs pose a substantial economic burden (fig 5). Countries face the implications of a workforce that never reaches its full productive potential, as well as the costs of treating and managing long term NCDs. Families are affected when wage earners cannot work or healthcare costs push households into poverty.

Yet, even the numbers in figure 5 do not represent the true costs of modern food systems, whose heavy environmental impact threatens the health of the planet and future generations. Global food production, responsible for up to a third of greenhouse gas emissions, is a major source of soil, air, and water pollution, while accounting for more than $70 \%$ of freshwater use and $40 \%$ of land use, and contributing to biodiversity loss. ${ }^{1516}$ These effects could rise by $50-90 \%$ by 2050 unless food systems are transformed. ${ }^{17}$ The type of food produced is also importantthe impact of ruminant meat production is around 100 times those of plant based foods. ${ }^{15}$

\section{Transforming food systems to tackle NCDs}

Real progress to prevent diet related NCDs across the life cycle requires radical food

\section{THE BALLOONING COSTS OF HEALTH IMPACTS IN FOOD SYSTEMS}
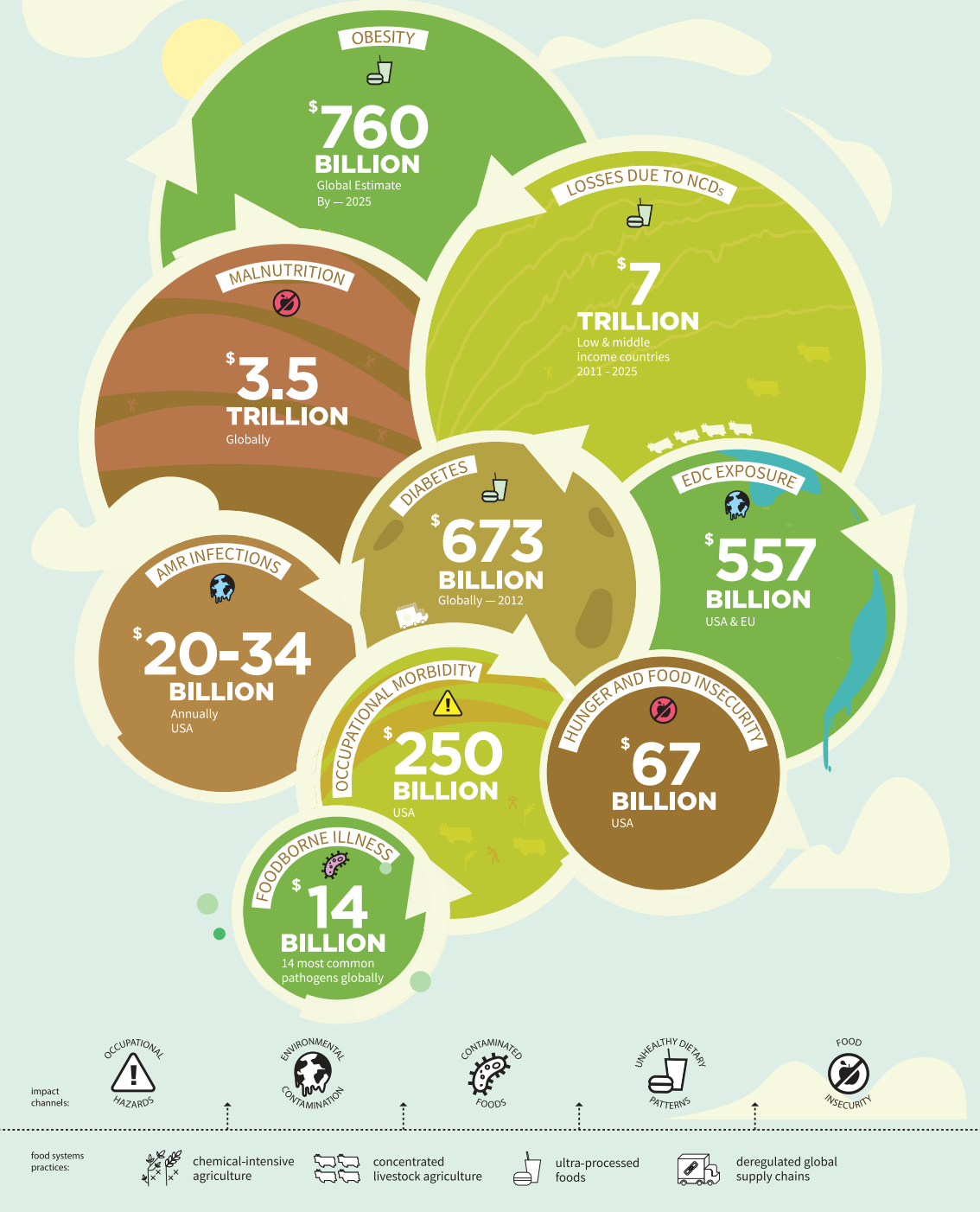

Fig 5 | The ballooning costs of health impacts in food systems. Recent estimates of the costs of impacts associated with food systems ${ }^{14}$ IPES-Food. Unravelling the food-health nexus: addressing practices, political economy, and power relations to build healthier food systems. Global Alliance for the Future of Food and IPES-Food, 2017 systems transformation so that nutritious, safe, affordable, and sustainable diets are available to all.

Food systems and the infrastructure on which they depend must be restructured. Reforms to the supply side of food systems in order to improve the availability of healthy sustainable diets are needed-from research and production through to processing, storage, transportation, marketing, and retailing.

Food, agriculture, and trade policieswhich were often originally devised to ensure quantity rather than quality of food-must remove incentives to produce less healthy foods and create incentives to produce diverse and nutritious foods using sustainable practices.

Investment must be made in green transport, storage, and distribution infrastructure to give access to perishable, nutrient rich foods, such as fruits and vegetables. Measures that affect demand for certain foods-what we buy, how we prepare it, and what we eat or throw away-are urgently needed. These should include actions to create healthy food environments, supported by nutrition education, especially in schools, ${ }^{18}{ }^{19}$ to ensure that even the most vulnerable people can access healthy diets. Taxes and subsidies-along with regulatory measures on food composition, marketing, labelling, and nutrition standards for food in schools and other public institutions-are among the tools available.

Although it is increasingly clear what needs to be done, less than a third of countries have fully implemented measures recommended by WHO-such as restricting marketing of unhealthy foods to children, taxing sugar sweetened drinks, or banning industrial trans fats (see box). Commercial interests, including the agri-food and drink industries, have large budgets to use on a variety of tactics-from lobbying decision makers to stirring public resistance-to undermine public health policy. ${ }^{20}$ Mechanisms are needed to protect governments against vested interests and ensure partnerships are in the interest of public health.

The challenges of achieving policy coherence and implementing multisectoral action across governments-in the face of competing priorities and budgetary constraints, short term political gain, and lack of accountability-should also be acknowledged, along with the challenges of collecting reliable data to inform policy and report on progress, or its lack. The role of activists in advocating for strong 
nutrition action, building public support, and holding government to account on their commitments is vital.

To accelerate progress, the United Nations Decade of Action on Nutrition (2016-2025), along with the 2030 Sustainable Development Agenda and Goals, and the Paris Agreement, present an unprecedented opportunity to transform food systems, eliminate malnutrition in all its forms, prevent diet related NCDs, and realise the human rights to food and health. $^{2122}$

We thank Karen McColl, Lina Mahy, and Jørgen Torgerstuen Johnsen for their contribution to this paper.

Contributors and sources: FB, AL, SO, VA, GS, $\mathrm{RR}, \mathrm{MA}$, and $\mathrm{AA}$ all participated in the drafting and reviewing of the paper. FB coordinated the overall preparation of the manuscript. AA analysed the data and provided the respective figures. All have read and agreed to the final version. The corresponding author attests that all listed authors meet authorship criteria and that no others meeting the criteria have been omitted. The authors alone are responsible for the views expressed in this article, which does not necessarily represent the views, decisions, or policies of WHO or the institutions with which the authors are affiliated.

For other articles in the series see www.bmj.com/ NCD-solutions

Competing interests: We have read and understood BMJ's policy on declaration of interest and have no relevant interest to declare.

Provenance and peer review: Commissioned; externally peer reviewed.

This article is part of a series proposed by the WHO Global Coordination Mechanism on NCDs and commissioned by The BMJ, which peer reviewed, edited, and made the decision to publish. Open access fees are funded by the Swiss Agency for Development and Cooperation, International Federation of Pharmaceutical Manufacturers and Associations (IFPMA), UNOPS Defeat-NCD Partnership, Government of the Russian Federation, and WHO.

Francesco Branca, director ${ }^{1}$

Anna Lartey, director ${ }^{2}$

Stineke Oenema, global coordinator ${ }^{3}$

Victor Aguayo, director of nutrition ${ }^{4}$

Gunhild A Stordalen, founder and executive chair ${ }^{5}$

Ruth Richardson, executive director ${ }^{6}$

Mario Arvelo, chair $^{7}$

Ashkan Afshin, assistant professor of health metrics sciences $^{8}$

${ }^{1}$ Department of Nutrition for Health and Development, WHO, Switzerland

${ }^{2}$ Nutrition and Food Systems Division, Food and Agriculture Organization of the United Nations, Italy

${ }^{3}$ United Nations System Standing Committee on

Nutrition secretariat, Italy

${ }^{4}$ UNICEF Programme Division, USA

${ }^{5}$ EAT, Norway

${ }^{6} \mathrm{Global}$ Alliance for the Future of Food, Canada

${ }^{7}$ Committee on World Food Security, Italy

${ }^{8}$ Institute for Health Metrics and Evaluation, USA

Correspondence to: FBranca

brancaf@who.int

\section{Actions to create healthy food environments}

While most countries report having dietary guidelines, labelling legislation, media campaigns promoting healthy diets, or nutrition counselling through primary healthcare, ${ }^{23}$ they could do more to create healthy food environments.

Structural actions to improve the food environment include-among others-implementing a ban on industrially produced trans fats; effective restrictions on marketing of unhealthy foods and beverages to children; ending inappropriate promotion (to parents) of foods for infants and young children; taxing sugar sweetened beverages or unhealthy foods; mandating simplified, interpretive front-of-pack nutrition labelling; and introducing nutrition standards for food served or sold in schools, hospitals, and other public institutions. These types of action are much less common-not one of the examples given has been implemented in more than a third of countries. ${ }^{23-26}$

The synergies of an approach to tackle multiple forms of malnutrition can be realised through "double duty" actions that tackle several forms of malnutrition at the same time. Examples include:

- Protection and promotion of optimal breastfeeding* and complementary feeding. This protects against undernutrition and can reduce the risk of developing overweight and diet related NCDs later in life, while breastfeeding can also protect mothers against some forms of cancer and other NCDs. Measures to promote breastfeeding, including banning advertising of breastmilk substitutes and extending paid maternity leave, increased exclusive breastfeeding in Vietnam, for example, from $20 \%$ to $62 \%$ in five years. ${ }^{27}$

- Enabling better access to safe drinking water protects against infectious diseases which exacerbate undernutrition while helping prevent obesity by providing an alternative to sugar sweetened beverages. Around 85 countries have taken measures, for example, to ensure that safe drinking water is available free of charge in schools. ${ }^{23}$

- School nutrition programmes can ensure children access diverse diets needed for healthy growth and development, while limiting their exposure to unhealthy foods, and can even work towards broader development goals. Brazil, for example, introduced nutrition standards for school food that require at least $30 \%$ of school food budgets to be spent buying from local family farmers.

*Defined as initiation of breastfeeding within one hour of birth, exclusive breastfeeding for the first six months of life, and introduction of nutritionally adequate and safe complementary solid foods at six months together with continued breastfeeding up to two years of age or beyond

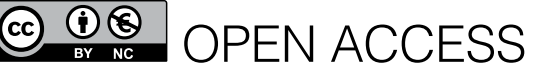

This is an Open Access article distributed under the terms of the Creative Commons Attribution IGO License (https://creativecommons.org/licenses/ by-nc/3.0/igo/), which permits use, distribution, and reproduction for non-commercial purposes in any medium, provided the original work is properly cited.

\section{D) Check for updates}

1 World Health Organization. World Health Statistics 2018. 2018. www.who.int/gho/publications/world_ health_statistics/2018/en.

2 World Health Organization. Noncommunicable diseases. Fact sheet. 2018. www.who.int/newsroom/fact-sheets/detail/noncommunicable-diseases.

3 Global Panel on Agriculture and Food Systems for Nutrition. Food systems and diets: facing the challenges of the 21st century. 2016. http://glopan. $\mathrm{org} / \mathrm{sites} /$ default/files/ForesightReport.pdf.

4 Food and Agriculture Organization of the United Nations, International Fund for Agricultural Development, Unicef, World Food Programme, World Health Organization. The state of food security and nutrition in the world 2018. 2018. www.fao.org/3/ 19553EN/i9553en.pdf.

5 United Nations System Standing Committee on Nutrition. Non-communicable diseases, diets and nutrition. 2018. www.unscn.org/uploads/web/news/ document/NCDs-brief-EN-WEB.pdf.
6 World Health Organization. Global nutrition targets 2025: stunting policy brief. 2014. www.who. int/nutrition/publications/globaltargets2025_ policybrief_stunting/en.

7 Turner C, Aggarwal A, Walls H, et al. Concepts and critical perspectives for food environment research A global framework with implications for action in low- and middle-income countries. Glob Food Secur 2018;18:93-101.

8 Unicef. From the first hour of life: making the case for improved infant and young child feeding everywhere 2016. www.unicef.org/publications/index_93027. html.

9 Guthold R, Stevens GA, Riley LM, Bull FC. Worldwide trends in insufficient physical activity from 2001 to 2016: a pooled analysis of 358 population-based surveys with 1.9 million participants. Lancet Glob Health 2018;6:e1077-86. www.thelancet.com/ journals/langlo/article/PIIS2214-109X(18)30357-7/ fulltext. doi:10.1016/S2214-109X(18)30357-7

10 World Health Organization. Obesity and overweight factsheet. 2018. www.who.int/news-room/factsheets/detail/obesity-and-overweight.

11 NCD Risk Factor Collaboration (NCD-RisC). Worldwide trends in body-mass index, underweight, overweight, and obesity from 1975 to 2016: a pooled analysis of 2416 population-based measurement studies in 128.9 million children, adolescents, and adults. Lancet 2017;390:2627-42. doi:10.1016/S01406736(17)32129-3

12 World Health Organization. Diabetes fact sheet. 2017. www.who.int/news-room/fact-sheets/detail/ diabetes. 
13 Institute for Health Metrics and Evaluation, University of Washington. GBD compare data visualization. 2016. https://vizhub.healthdata.org/gbd-compare.

14 IPES-Food. Unravelling the food-health nexus: addressing practices, political economy, and power relations to build healthier food systems. Global Alliance for the Future of Food and IPES-Food, 2017.

15 Clark M, Tilman D. Comparative analysis of environmental impacts of agricultural production systems, agricultural input efficiency and food choice. Environ Res Lett 2017;12:6. doi:10.1088/17489326/aa6cd5

16 Scherr S, McNeely J. Farming with nature: the science and practice of ecoagriculture. Island Press, 2012.

17 Springmann M, Clark M, Mason-D'Croz D, et al. Options for keeping the food system within environmental limits. Nature 2018;562:519-25. doi:10.1038/s41586-018-0594-0

18 Silveira J, Taddei J. Guerra PH, Nobre MR. The effect of participation in school-based nutrition education interventions on body mass index: a meta-analysis of randomized controlled community trials. Prev
Med 2013:56(3-4):237-43. doi:10.1016/j. ypmed.2013.01.011

19 Meiklejohn S, Ryan L, Palermo C. A systematic review of the impact of multi-strategy nutrition education programs on health and nutrition of adolescents. J Nutr Educ Behav 2016;48:631-646. e1. doi:10.1016/j.jneb.2016.07.015

20 Moodie R, Stuckler D, Monteiro C, et al. Lancet NCD Action Group. Profits and pandemics: prevention of harmful effects of tobacco, alcohol, and ultra-processed food and drink industries. Lancet 2013:381:670-9. doi:10.1016/S01406736(12)62089-3

21 Food and Agriculture Organization of the United Nations. Rome declaration on nutrition. 2014. www. fao.org/3/a-ml542e.pdf.

22 World Health Organization. Heads of state commit to lead response to beat noncommunicable diseases, promote mental health. 2018. www.who.int/newsroom/detail/27-09-2018-heads-of-state-commit-tolead-response-to-beat-noncommunicable-diseasespromote-mental-health
23 World Health Organization. Global nutrition policy review 2016-2017. 2018. www.who. int/nutrition/publications/policies/global_nut_ policyreview_2016-2017/en.

24 World Health Organization. Assessing national capacity for the prevention and control of noncommunicable diseases: report of the 2017 global survey. 2018. www.who.int/ncds/surveillance/ncdcapacity/en.

25 World Health Organization. Global database on the implementation of nutrition action (GINA). 2018 www.who.int/nutrition/gina/en.

26 World Cancer Research Fund. NOURISHING Database. 2018. www.wcrf.org/int/policy/ nourishing-database.

27 WHO. Viet Nam breastfeeding campaign normalizes practice, improves rates. 2016. www.who.int/en/newsroom/feature-stories/detail/viet-nam-breastfeedingcampaign-normalizes-practice-improves-rates.

Cite this as: $B M J$ 2019;365:1296

http://dx.doi.org/10.1136/bmj.l296 